\title{
Development of an intelligent, context sensitive and collaborative authoring system for context effect- based education
}

\section{Développement d'un outil intelligent pour la scénarisation}

\section{collaborative en contexte}

\section{Claire Anjou ${ }^{1}$, Fatma Miladi ${ }^{1}$, Valéry Psyché ${ }^{1}$, Jacqueline Bourdeau ${ }^{1}$, Thomas Forissier ${ }^{2}$, Alain Stockless ${ }^{3}$}

\author{
${ }^{1}$ Université TELUQ, Montréal, Québec, Canada anjou.claire@gmail.com, fatma.miladi@teluq.ca, \\ valery.psyche@teluq.ca, jacqueline.bourdeau@teluq.ca \\ ${ }^{2}$ CRREF, Université des Antilles, Guadeloupe, France tforissi@espe-guadeloupe.fr \\ ${ }^{3}$ UQAM, Montréal, Québec, Canada, stockless.alain@uqam.ca
}

\begin{abstract}
The inclusion of context in education is important to allow teachers and students to discover the diversity, the importance and the role of context in the teaching and learning. To do so, a pedagogical model based on context effects and called the 'Clash model' has been developed and experimented. To facilitate experimental and research activity around this model, several numeric tools are needed. The Mazcalc (Context gap calculator), is a numeric tool that can model a studied object in multiple distinct geographical contexts and calculate gaps between the contexts of the given object according to several parameters and themes. The objective is to use this calculation to provide information about the differences and similarities between the two contextual instantiations of the studied object. The Mazcalc will then communicate with a CEM (Context Effect Manager) that will provide recommendations about the relevance of the setting up of a context sensitive and collaborative pedagogical experiment between the two contexts. The Mazcalc has already been developed and this paper focuses on the work in progress regarding the advances of the TEEC project1, which concerns the creation of the CEM and the authoring system.

RÉSUMÉ. L'intégration du contexte dans l'éducation est importante pour permettre aux enseignants et aux étudiants de découvrir la diversité, l'importance et le rôle du contexte dans l'enseignement et l'apprentissage. Pour ce faire, un modèle pédagogique basé sur les effets de contexte et appelé le 'modèle Clash' a été développé et expérimenté. Pour faciliter les activités de recherche et les expérimentations autour de ce modèle, plusieurs outils numériques sont nécessaires. Le Mazcalc (calculateur de contexte) est un outil numérique qui permet de modéliser un objet étudié dans plusieurs contextes géographiques distincts et de calculer les écarts entre les contextes de l'objet en fonction de plusieurs paramètres et thèmes. L'objectif est d'utiliser ce calcul pour fournir des informations sur les différences et les similitudes entre les deux instanciations contextuelles de l'objet d'étude. Le Mazcalc communiquera ensuite avec un CEM (Gestionnaire d'effet de contextes) qui fournira des informations sur la pertinence de la mise en place d'une expérimentation pédagogique collaborative sensible au contexte impliquant des apprenants des deux contextes modélisés. Le Mazcalc a déjà été développé et cet article se concentre sur les travaux en cours concernant les avancées du projet TEEC1 sur la création du CEM et du système auteur pour assister la scénarisation.
\end{abstract}

KEYWORDS. Context effect, authoring system, education, clash model, collaboration, pedagogical design. MOTS-CLÉS. Effet de contexte, système auteur, éducation, modèle clash, collaboration, design pédagogique.

\section{Introduction and theoretical framework}

The relationship between education and context led to the development of innovative approaches integrating educational technology concepts from pedagogical design to contextualised and

\footnotetext{
${ }^{1}$ https://teec.teluq.ca/en/
} 
collaborative teaching using digital technology and educational tools. These approaches find their place at the crossroads of computer science and contextualisation of science education. Within this framework, a teaching and learning model based on context effects has been created : the Clash model [1]. Several studies regarding various aspects of research work around this model have been carried out:

- The experimentation of this pedagogical model [2].

- The analysis methodology of experiments [3].

- The designing and development of digital tools to help and participate in the creation of a context-aware intelligent tutoring system $[1,4,5]$.

The Clash model is based on the context effects theoretical framework [6]. According to Forissier, context effects are phenomena that occur when a discrepancy between the conceptions held by two or more actors in the didactic situation (teacher, student, textbook, curriculum, media support...) is revealed. They can result in the emergence of cognitive or socio-cognitive conflicts and can be used to promote teaching. Education based on context effects was developed with the ambition of creating teaching situations that would favour the emergence of context effects phenomena. In order to do this, the principle of context effects-based teaching consists of bringing together learners living in more or less distant geographical contexts, where the common object they are studying may be perceived in very different ways due to the diversity of their context. The collaboration between these learners allows them to share their conceptions, and to become aware of the differences between their conceptions of the object of study. The context effects phenomena may emerge during didactic interactions and take the form of emotions or particular interactional patterns, but above all they allow learners to become aware of the diversity of contexts, the diversity of natures of the object they are studying, and the diversity of ways it is possible to study it.

In order to conceptualise such a pedagogical model, it is necessary to:

- Validate the underlying theories by testing the model robustness at different academic levels, in different disciplines, and in multiple geographical context;

- Formalise and normalise the data of experiments organisation and the follow-up of the experiment progress;

- And facilitate its integration within the educational community.

- Be linked to a database that will gradually be implemented thanks to the created scenarios

For now, multiple experiments based on the Clash model were realised and analysed, in the TEEC project. At the same time, a digital tool for the modelling and calculation of context gaps was developed and implemented (the context gap calculator named Mazcalc). It allows to identify parameters and themes with big differences (regarding a same studied object in two distinct geographical contexts) and is used to guide pedagogical experiments.

The final objective is to improve the learning process by creating a digital tool participating, from the inception to the achievement, in the design of leaning scenarios, based on context effects. This tool must also offer the possibility to track data collection and analysis to be able to improve itself regarding the recommendation that it has provided to the users for the scenario designing, and be linked to a database that will progressively enrich with data from learning scenarios, experiments and research.

\section{Research focuses}

Until now, works regarding context effect-based teachings, have given little importance to pedagogical scenarios. Yet, this aspect is very important and has to be of further studied. Indeed, the very nature of the pedagogical Clash model requires collaborative (i.e., between stakeholders from 
both contexts) and contextual (i.e., based on distinct contexts) scenarios. Indeed, the scenarios have to be constructed collaboratively between teachers or instructional designers of both contexts, and include collaboration between learners. They must also take into account several aspects such as the synchronisation of activities and resources between both contexts, the technical constraints, the digital technologies for exchanges, or the physical and pedagogical contexts. Otherwise, the realisation of experiments can be compromised. Actually, the analysis of previous experiments has highlighted weaknesses into the organisation process that have impacted experiments and that might have been avoided thanks to a formal and rigorous pedagogical scenario writing process.

This study focuses on work in progress regarding the development of the CEM (Context Effect Manager) and the designing of a digital tool for the creation and implementation of context effectbased pedagogical scenarios: the authoring system. The authoring system tool has to be imagined with respect to multiple fundamental characteristics including three main ones which are the following:

- It has to be linked to the CEM, that is itself linked with the Mazcalc (the context gap calculator) in order to provide the users with recommendations, depending on the pedagogical contexts involved and the studied object models in both contexts (Figure 1).

- It has to be multi-context aware and collaborative.

- It has to provide a follow-up of the experiment progress and data analysis for its selflearning of consistency between initial recommendations and effective results.
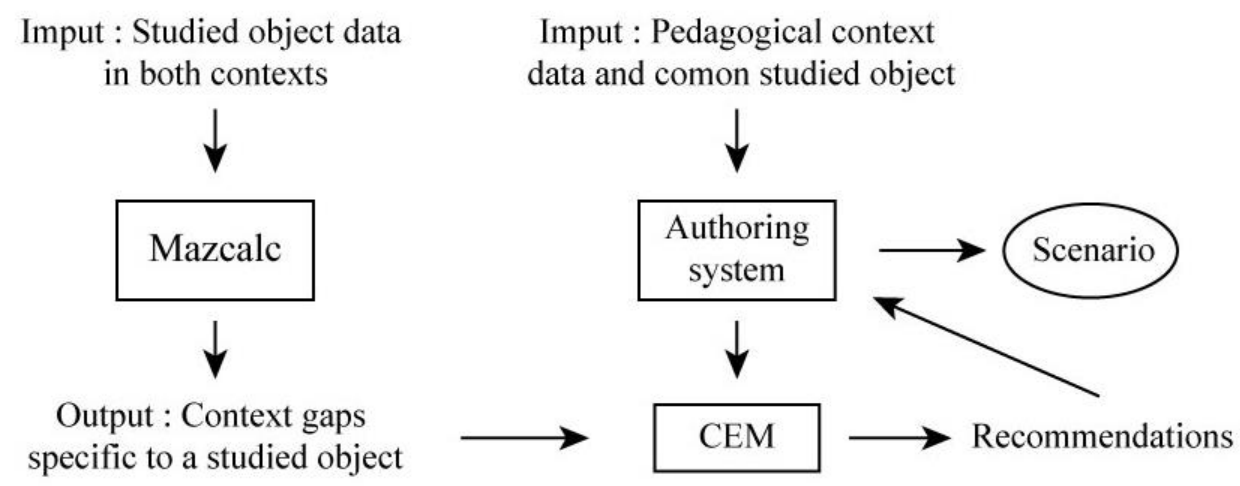

Figure 1. Relationships between the Mazcalc, the authoring system and the Context Effect Manager (CEM).

\section{Methodology}

This research is based on the Design-based research methodology (DBR). This methodology allows to bridge the gap between laboratory and field research, and enables a process by which theory and practice can evolve together, according to a design process [7]. It is based on system science principles and can be characterised as a microsystemic methodology. DBR aims at comprising the complexity of an authentic situation thanks to the feedback of loops mechanisms where the analyse and result of each loop can be reinvested in the next one to change the design and behaviour of the system [8].

This methodology has already been formally tested in the TEEC project. Each experiment has been based on lessons learned from the previous one. In parallel, conceptual tools have been developed and improved through their use in the different experiments.

In this study, the DBR methodology allows to: 
- conciliate the designing and development of the CEM and the authoring system and their use with the educational community thanks to multiple loops of tests.

- use the results of the previous experiments to design a template that will best meet the needs of the pedagogical model.

In order to establish a common understanding of the authoring system to develop, an ontology has been initiated with the GMOT2 software. At the same time, an Excel prototype of the tool has been created. To validate those products, interviews with various actors of the TEEC project will be set up to test the Excel template and evaluate the robustness of the vocabulary used. These interviews will involve teachers, students, researchers and instructional designers in order to cover the various uses that can be made of the tool. Also, some of the previous iterations of experiments will be implemented in the Excel tool by a researcher involve in the experiment to verify its overall coherence.

\section{Preliminary results}

For now, several steps were accomplished, but the work is still in progress. The Mazcalc has been designed and is currently developed and tested [5]. It models context gaps regarding a given studied object by calculating the differences between the normative value accorded to the parameters in each context. The Mazcalc outputs correspond to a value between 0 and 1 for each parameter used for the context modelling, or for each group of parameters organised according to a topic. Then, it communicates with the CEM that translates the value into an understandable recommendation for the instructional designer. The recommendations for the creation of scenarios are visible through the authoring system.

The UML specifications of the authoring system have been designed to help a learning designer to: describe the learning context; define the academic level, the discipline, the learning objectives and the learning object. The CEM has been implemented thanks to CLIPS ${ }^{3}$ (C Language Integrated Production System). It is a rule-based expert system composed of 3 components: (1) a rule base, a long-term memory containing rules in the form IF THEN, (2) a fact base, which takes the place of a short-term memory containing facts, and (3) an inference engine that links the rules and the facts towards a conclusion. Structured facts have been defined and added to the fact base, and the rules have been coded, allowing the inference engine to provide recommendations if the conditions of the rule are verified.

The knowledge model for the authoring system has been created on the GMOT software. The template of the authoring system has been designed on the Excel software. Also, the collaborative authoring system contains 10 sections organised as follows. The sections are to be filled collaboratively with authors of the scenario in both contexts.

(1) The preliminary information: they allow to specify the pedagogical and geographical context and to define the common object studied. The CEM uses this preliminary information as well as data retrieved from the Mazcalc to provide recommendations regarding the scenario (Figure 1).

(2) Technical information of the pedagogical scenario: it concerns mainly the physical and numeric spaces, the needed material and the human resources.

(3) The class organisation: the section aims to define the themes on which learners will have to work and to organise the collaboration between learners in both contexts.

\footnotetext{
${ }^{2}$ GMOT is a tool developed by the TELUQ University (https://gmot.teluq.ca/)

${ }^{3}$ http://www.clipsrules.net/Downloads.html
} 
(4) The scenario presentation with situational settings and guidelines.

(5) The pedagogical information including the covered concepts, competencies, pedagogical strategies, project objectives, source and verification of the pedagogical content.

(6) The learners' productions: what will the student have to do at the end of the project?

(7) The evaluations: what will the learners be assessed on during the project?

(8) The schedule of the project: where the learning designer will have to ensure the synchronicity between both contexts.

(9) Research data: if the project is led in the framework of a research, what data will be collected, for what purpose, and how?

(10) And finally, a list of elements to check before the implementation of the project. This list is built according to the constraints and obstacles observed in the previous experiments and which had affected the smooth running of the project.

The Excel template is shaped as a form. The testing of this template will be realised during interviews with users (education actors) from diverse level of the educative sphere, and the analyses of interviews will allow us to improve the template thanks to the DBR methodology.

\section{Conclusion and future work}

Once the authoring system template and the recommendations will be adjusted according to the users' interviews and feedback, we will be able to develop our tool in the form of a digital application. Then it will be possible to link the Mazcalc outputs to the CEM. Once the connection between Mazcalc and CEM will be established, the authoring system will be tested with the existing pedagogical scenarios applied in the previous experiments. Also, the research data and results of the previous experiments will be implemented in the authoring system. Thanks to that, it will be possible to verify the consistency between the CEM recommendations provided and the experiment results. The verification will allow to adjust the recommendations if necessary. All these data will be stored in a global database of object and context models, learning scenarios, and research data. Ultimately, this will lead to a bank of validated learning scenarios that teachers will be able to use to set up pedagogical projects based on the Clash model.

\section{Bibliography}

[1] Forissier, T., Bourdeau, J., Mazabraud, Y., \& Nkambou, R., Modeling Context Effects in Science Learning: The CLASH Model. In P. Brézillon, P. Blackburn, \& R. Dapoigny (Eds.), Modeling and Using Context: 8th International and Interdisciplinary Conference, CONTEXT 2013, Annecy, France, October 28 -31, 2013, Proceedings (pp. 330-335). Berlin, Heidelberg: Springer, 2013

[2] Chartofylaka, L., Anciaux, F., Candau, O.-S., Jeannot-Fourcaud, B., Carignan, I., \& Saint-Pierre, A. Il était une fois des contes en contextes: retour sur une expérimentation au primaire en Guadeloupe et au Québec. Contextes et Didactiques(11), 67-108, 2018.

[3] Le Bail, C., Baker, M., Detienne, F., Bernard, F.-X., Chartofylaka, L., \& Forissier, T., Grounding and knowledge elaboration across cultural and geographical contexts: An exploratory case study. Learning, Culture and Social Interaction, 28, 2021. https://doi.org/10.1016/j.1csi.2020.100477

[4] Anjou, C., Forissier, T., Bourdeau, J., Mazabraud, Y., Nkambou, R., \& Fournier, F., Elaborating the Context Calculator: A Design Experiment in Geothermy. Paper presented at the International and Interdisciplinary Conference on Modeling and Using Context, 2017.

[5] Psyché, V., Anjou, C., Fenani, W., Bourdeau, J., Forissier, T., \& Nkambou, R., Ontology-Based Context Modelling for Designing a Context-Aware Calculator. Paper presented at the ITS, Montreal, Canada, 2018.

[6] Merlo-Leurette, S., \& Forissier, T. La contextualisation dans l'enseignement des sciences et techniques en Guadeloupe. Grand N, 83, 19-26, 2009.

[7] Sandoval, W. A., \& Bell, P., Design-Based Research Methods for Studying Learning in Context: Introduction. Educational Psychologist, 39(4), 199-201, 2004. https://doi.org/10.1207/s15326985ep3904_1 
[8] Bourdeau, J., The DBR methodology for the study of context in learning. In P. Brézillon, R. Turner, \& C. Penco (Eds.), Modeling and Using Context. CONTEXT 2017. Lecture Notes in Computer Science (Vol. 10257, pp. 541553): Springer, 2017. 